\title{
Biosensor Design for Detection of Mercury in Contaminated Soil Using Rhamnolipid Biosurfactant and Luminescent Bacteria
}

\author{
Aziz Babapoor $\mathbb{D}^{1},{ }^{1}$ Reza Hajimohammadi, ${ }^{2}$ Seyyed Mohammad Jokar, ${ }^{3}$ and Meysam Paar ${ }^{1}$ \\ ${ }^{1}$ Department of Chemical Engineering, University of Mohaghegh Ardabili, P.O. Box 179, Ardabil, Iran \\ ${ }^{2}$ Department of Chemical Engineering, Ahar Branch, Islamic Azad University, Ahar, Iran \\ ${ }^{3}$ Department of Chemical,Petroleum and Gas Engineering, Shiraz University of Technology, Shiraz, Iran \\ Correspondence should be addressed to Aziz Babapoor; babapoor@uma.ac.ir
}

Received 7 July 2020; Revised 30 September 2020; Accepted 10 November 2020; Published 25 November 2020

Academic Editor: Claudio Cameselle

Copyright (c) 2020 Aziz Babapoor et al. This is an open access article distributed under the Creative Commons Attribution License, which permits unrestricted use, distribution, and reproduction in any medium, provided the original work is properly cited.

\begin{abstract}
In this study, a biosensor is designed to remove mercury as a toxic metal contaminant from the soil. The rhamnolipid biosurfactant was used to extract the mercury sorbed to soil to the aqueous phase. An immobilized bioluminescent bacterium (Escherichia coli MC106) with pmerRBPmerlux plasmid is assisted for mercury detection. A significant decrease in luminescence level was observed in a biosensor system containing contaminated soil sample extract. The concentrations of extracting mercury are well correlated with the mercury toxicity data obtained from experimental biosensor systems according to the RBL value. The optimum aeration rate of $20 \mathrm{ml} / \mathrm{min}$ was obtained for the biosensor systems. The advantage of such a biosensor is the in situ quantification of mercury as a heavy metal contaminant in soils. Therefore, this system could be proposed as a good biosensor-based alternative for future detection of heavy toxic metals in soils.
\end{abstract}

\section{Introduction}

Soil pollution is defined as the existence of toxic substances at high concentrations. All soils contain various contaminants such as metals, inorganic ions, salts, PAHs, etc. These compounds are mainly formed through soil microbial activity [1]. Furthermore, various compounds discharge into the soil from the atmosphere. These contaminants are stored in plants by growing on contaminated soils [2, 3]. Metals, especially mercury, are the most essential materials that contaminate the soils. The remediation of mercury-contaminated soils is obligatory due to its high toxicity $[3,4]$. Mercury poisoning is very harmful, and the impacts of mercury contact can be severe $[4,5]$. Consuming the fish that is high in mercury is related to an increased danger of cancer $[5,6]$. The primary sources of mercury are metal processing, mining activities, fossil fuel burning, chloride derivatives, and fertilizers $[2,3]$. However, it seems to be the atmospheric precipitation is the main source of metallic pollution [7].
There are many methods for eliminating metallic contaminants, especially mercury, from soils. These methods are including the coagulation of soluble substances and adsorption on active carbon $[8,9]$ and the emulsification process by surfactants [9]. Physical, chemical analysis, and atomic absorption spectroscopy are commonly used to detect heavy metals in the soil [10]. Unfortunately, the analysis of toxic materials by these methods is difficult and expensive [11]. Also, the physicochemical analysis of the toxicity of the materials could not provide the information to evaluate the toxicity of the material $[10,12]$. Although many methods are used for the detection of heavy metals in soil, there has been little study about microbial and biological methods. Therefore, alternative methods should be investigated. Biosurfactants are considered a possible green compound that increases the rates of heavy metals extraction from the soil to the aqueous phase [13]. Luminous bacteria are mainly defined as light-emitting microorganisms. Due to the presence of a luxCDABE gene, this group of bacteria generates luciferase enzyme and consequently produce light 
in the visible spectrum. This ability has led to the use of these bacteria as whole-cell sensors for the detection of various types of environmental pollutants $[14,15]$. The principle of luminescence bacteria is based on changes in the severity of light production under the influence of toxic substances [16]. Since the luminescence bacterial is directly related to cellular respiration, any inhibition of cellular metabolism due to toxicity resulted in a decrease in the emission of light in the affected cells, and it is an indication of unusual conditions. It may be the toxicity of the ecosystem [8, 14]. Recently, recombinant luminescent strains (Lux CDABE genes) were used as a detection system for environmental pollutants, especially in water and soils [17]. This detection system's advantages are comfortable performance, rapid responses, and low costs [18].

Zou et al. [19] proposed a method involving the use of $\mathrm{pH}$ control and rhamnolipid to enhance the efficacy of removing aging from EK correction. By cycling electrolytes, exchanging electrodes, and implementing $\mathrm{pH}$ electrolyte 7 of $\mathrm{pH}$, with high values of $12.12 \%, 10.48$, and 14.00 , respectively, with increasing electrolyte cycling, electrode exchange was successfully improved and compared with 0.35 achieved with traditional EK treatment. The effect of adding rhamnolipid on the removal of PK EK was also investigated. In another study, Sun et al. [20] showed that a combination of $\mathrm{EK}$ and Fe/C-PRB is effective and promising in eliminating persistent organic pollutants (POPs) from contaminated soil by reinforcing rhamnolipid. Hansen et al. [21] produced three significant biosensor vectors to detect low mercury concentrations. These biosensors offer three different reporting gene systems, LuxCDABE, lacZYA, and GFP, with a combination of Pmer. Furthermore, the structures were placed in mini-Tn5 delivery carriers, so there is an option for Gram-negative bacteria to be used as biosensors host cells. Rasmussen et al. [22] examined two different types of soil (forest soil and beech soil) with $2.5 \mathrm{mg}$ of mercury (II) in microscopes and the frequency of mercury-resistant heterogeneities. In agricultural soils, the initial concentration of available mercury was estimated at $40 \mathrm{mgg}^{-1}$. This concentration did not change during the first three days and, at the same time, increased resistance levels and decreased diversity. The available mercury concentration subsequently decreased rapidly and remained exactly above the detection level $(0.2 \mathrm{~g} / \mathrm{g})$ for the remaining experiments. As a possible result of reduced mercury selection pressure, resistance and variety gradually return to preexposure values. In the soil of the beech forest, the concentration of available mercury was observed to be about $20 \mathrm{mg} / \mathrm{g}$ G1 during the experiment. This concentration does not, in any way, change the strength or variety. This study showed that measuring using a merLux biosensor is a useful and sensitive tool for estimating the bioavailability available in the soil [22].

Corbisier et al. $[23,24]$ designed biosensors that emit light in the presence of specific metals. They used a copper biosensor (AE1239) and zinc, cadmium, and lead biosensor (AE1433) to detect the presence of available metals in flyashes (IFA) and soils. The produced biosensors could successfully evaluate the bioavailability of heavy metals. These biosensors were very relevant since no pretreatment of the soils and IFA was needed. Leth et al. designed a biosensor for the detection of $\mathrm{Cu}$, using luxCDABE strain from Vibrio Fischeri [25, 26]. Enzyme-, DNA-, immune-, whole-cellbased biosensors were designed by Turdean et al. for the detection of heavy metals such as $\mathrm{Pb}, \mathrm{Cd}$, and $\mathrm{Ni}[27,28]$. Jouanneau et al. improved heavy metal detection using different strains of $E$. coli as bioluminescence bacteria $[29,30]$.

Kursunlu et al. and Sulak et al. designed and prepared fluorescent alkyl-chloride boradiazaindacene (Bodipy) based sensors [31-33]. They showed that Calix [4]-B (obtained by click reaction [31] and a fluorescent Bodipy with alkylchloride terminal) [32], aryl-amine (containing azacrown ether ring and Bodipy) and on/off rhodamine-Bodipy (RB) [33] are appropriate sensors which could be used for high sensitivity detection of mercury ion.

Despite various studies on the extraction of mercury from contaminated soil, much of the focus has been on the use of chemical surfactants. However, the fundamental gap in the use of various methods has not yet been addressed. Thus, biosurfactant rhamnolipid, which has not been evaluated so far, was used in this study. Despite all this research, the mescore genome from $E$. coli bacteria has not been used for mercury so far, except in very few cases where soil extraction has not been fully and accurately studied. The extraction of rhamnolipid can be used to increase the extraction rate. Therefore, the current study focuses on the biosensor design for the detection of mercury toxicity using rhamnolipid biosurfactants and recombinant bioluminescent bacteria as biosensing systems.

\section{Materials and Methods}

\subsection{Materials}

2.1.1. Soil Preparation. Figure 1 shows the image of the light production of bioluminescence bacteria during the bacteria growth. The soil sample was collected from a garden located in the Ahar industrial city, East Azerbaijan, Iran. The selected soil sample was sieved at $1 \mathrm{~mm}$ to remove the coarse elements before the tests. The soil heavy metal contaminants are measured using atomic absorption spectroscopy. For evaluating the mercury toxicity, $100 \mathrm{ppm}$ of mercuric chloride is added to $50 \mathrm{~g}$ of the soil sample at constant $\mathrm{pH}$ (7.2). The analyzed data are presented in Table 1.

2.1.2. Production of Biosurfactants. The rhamnolipid biosurfactant is applied as an emulsifier for improving the efficiency of mercury extraction from the soil into the aqueous phase. Rhamnolipid was a mixture of mono- and dirhamnolipid at an approximate ratio of $1: 1$. The CMC (Critical Micelle Concentration) and HLB (Hydrophilic Lipophilic Balance) value of produced rhamnolipid were $180 \mathrm{mg} / \mathrm{l}$ and 9.5, respectively. The producing procedure for rhamnolipid biosurfactant is mentioned in our previous work [34]. The biosurfactant was characterized using TLC spectroscopy. Figure 2 shows the results of TLC spectroscopy for mono- and dirhamnolipid and then compared with the standard data [35]. Also, Table 2 shows the retention 


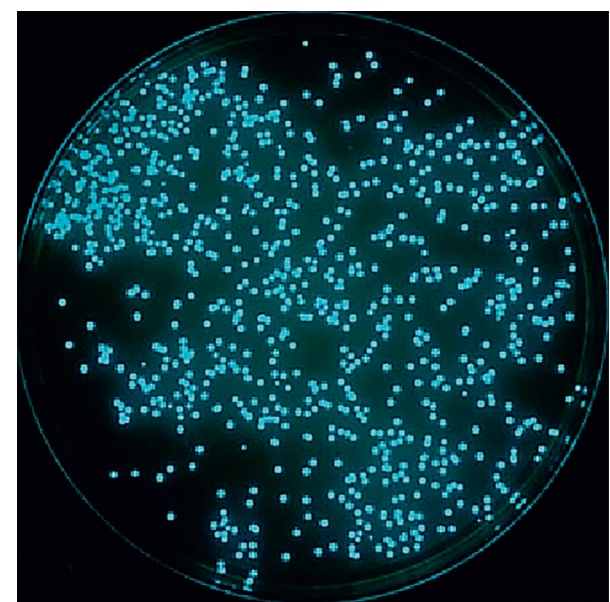

FIGURE 1: Luminescent bacteria growing on a nutrient agar plate in the dark room.

TABLE 1: Soil characteristics and analysis.

\begin{tabular}{lc}
\hline Parameter & Concentration (\%) \\
\hline Fine sand & 23 \\
Large sand & 72 \\
Silt & 2.5 \\
Clay & 2.5 \\
Organic compounds & 3 \\
Cd & 0.23 \\
Ni & 1.2 \\
Zn & 0.7 \\
Cr & 0.8 \\
\hline
\end{tabular}

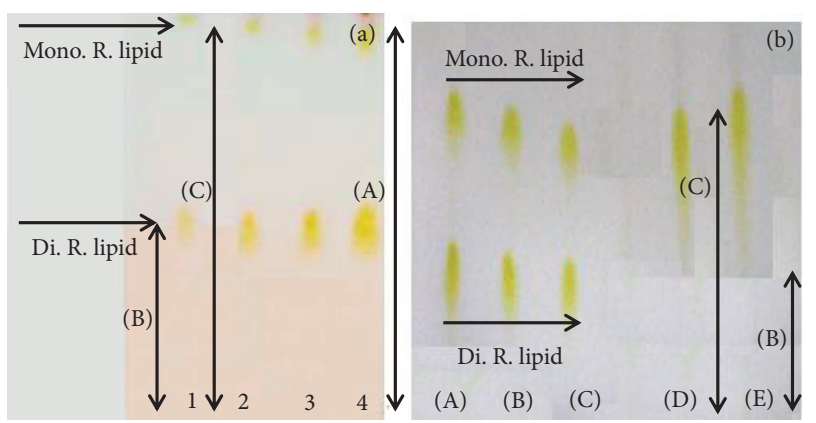

FIgURE 2: TLC of the mono- and dirhamnolipid: (a) produced; (b) reported in research studies.

TABle 2: Retention factor of produced rhamnolipid.

\begin{tabular}{lcc}
\hline$R_{f}$ values & $R_{f 2}(\mathrm{c} / \mathrm{a})$ & $R_{f 1}(\mathrm{~b} / \mathrm{a})$ \\
\hline Produced & $\mathbf{0 . 9}$ & 0.45 \\
Reported & $\mathbf{0 . 6 8}$ & 0.35 \\
\hline
\end{tabular}

factor $\left(R_{f}\right)$ of produced rhamnolipid. The dried transparent glass beads with the diameter range of $300-500 \mu \mathrm{m}$ were purchased from Zhejiang Pujiang Jingsheng Crystal Co., Ltd, China. Polypropylene tubes were purchased from India MART Co., Noida, India. All materials for the immobilization process of bacteria were purchased from Sigma Aldrich Co., Germany.

2.2. The Immobilization of Luminescence Bacteria. Polypropylene tubes' outer diameter and length are 8.5 and $10 \mathrm{~mm}$, respectively. The polypropylene tubes and glass beads were washed with water, autoclaved, and completely dried in a drying oven before use after autoclaving was used for immobilization of bioluminescence bacteria. Furthermore, the dried transparent glass beads with a diameter range of $300-500 \mu \mathrm{m}$ were assisted in increasing the sensitivity of the biosensor. Each polypropylene tube contains $0.1 \mathrm{~g}$ of glass beads. The bioluminescent bacterium is a recombinant pmerRBPmerlux plasmid was transformed into the Escherichia coli strain MC 1061 introduced by Rantala et al. At the concentration of the cells was between $1 \times 10^{9}$ and $2 \times 10^{9}$ cells/tube, the high response of the E. coli cells was obtained [36]. Escherichia coli MC106 cells were grown at $37^{\circ} \mathrm{C}$ in a shaking incubator (Model: GFL 3032, Germany) at $200 \mathrm{rpm}$. The incubator contains Luria Bertani (LB) (Sigma Aldrich Co. Germany) medium supplemented with $50 \mathrm{mg} / \mathrm{l}$ streptomycin. The optical density should reach 4 during the incubation process. After incubation, $100 \mathrm{ml}$ of culture medium was centrifuged at $350 \mathrm{rpm}$ at room temperature for $20 \mathrm{~min}$. The collected cells were suspended in $1 \mathrm{ml}$ of fresh LB medium. After autoclaving, the mixture of $15 \mathrm{~g} / \mathrm{l}$ micro agar (Sigma Aldrich Co. Germany) and $25 \mathrm{~g} / \mathrm{l}$ LB medium should be maintained at $40^{\circ} \mathrm{C}$ in the water bath during the immobilization procedure. Pipes containing $0.1 \mathrm{~g}$ of glass beads were filled with $200 \mu \mathrm{l}$ of cell mixture. The cellular mixture in the tubes was stabilized at $25^{\circ} \mathrm{C}$.

2.3. Bioreactor Design. The bioreactor setup is shown in Figure 3. As shown in this figure, a stainless-steel bioreactor $(v=100 \mathrm{ml})$ equipped with a water jacket was used to maintain the inside temperature at a constant value. The bioreactor was filled with $25 \mathrm{ml} \mathrm{LB}$ medium. The sparge tube is connected to the inlet of the reactor vessel for preparing fresh air. Furthermore, two connections were available for gas venting and injection of the toxic samples (mercury). A fiber-optic probe was attached to the biosensor kit. A sensitive luminometer (Model: Smart Line TL Tube Luminometer, UK) was joined to the end of a fiber-optic probe to measure the bioluminescence (BL) signal from the immobilized cells. This system was connected to a PC in order to collect real-time data (Figure 3). The schematic of the biosensor kit is shown in Figure 4.

2.4. Extraction of Mercury Using Rhamnolipid. The soil samples were washed with fresh water, sterilized, and dried in an oven. $5 \mathrm{~g}$ of the soil samples (contain $200 \mathrm{ppm}$ of mercury chloride) was mixed with $50 \mathrm{ml}$ of rhamnolipid with different concentrations $(0.5,1,1.5,2,2.5$, and $3 \mathrm{~g} / \mathrm{l})$. To increase the efficiency of mercury extraction, soil slurry samples were mixed at $200 \mathrm{rpm}$ and room temperature $\left(25^{\circ} \mathrm{C}\right)$. After the extraction process, samples were centrifuged at $345 \mathrm{rpm}$ to remove particles. The supernatants were 

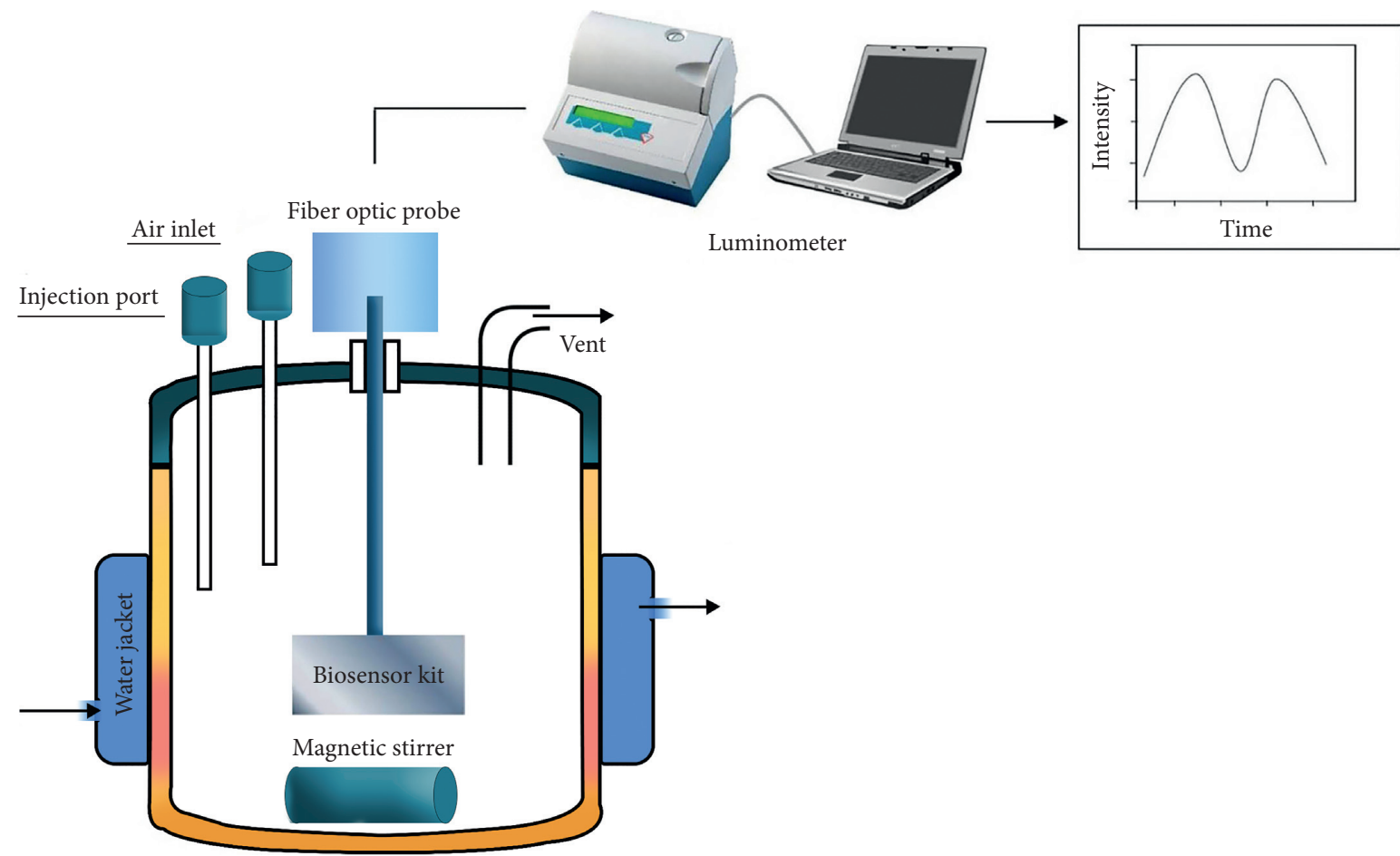

Figure 3: Biosensor system used in this study.

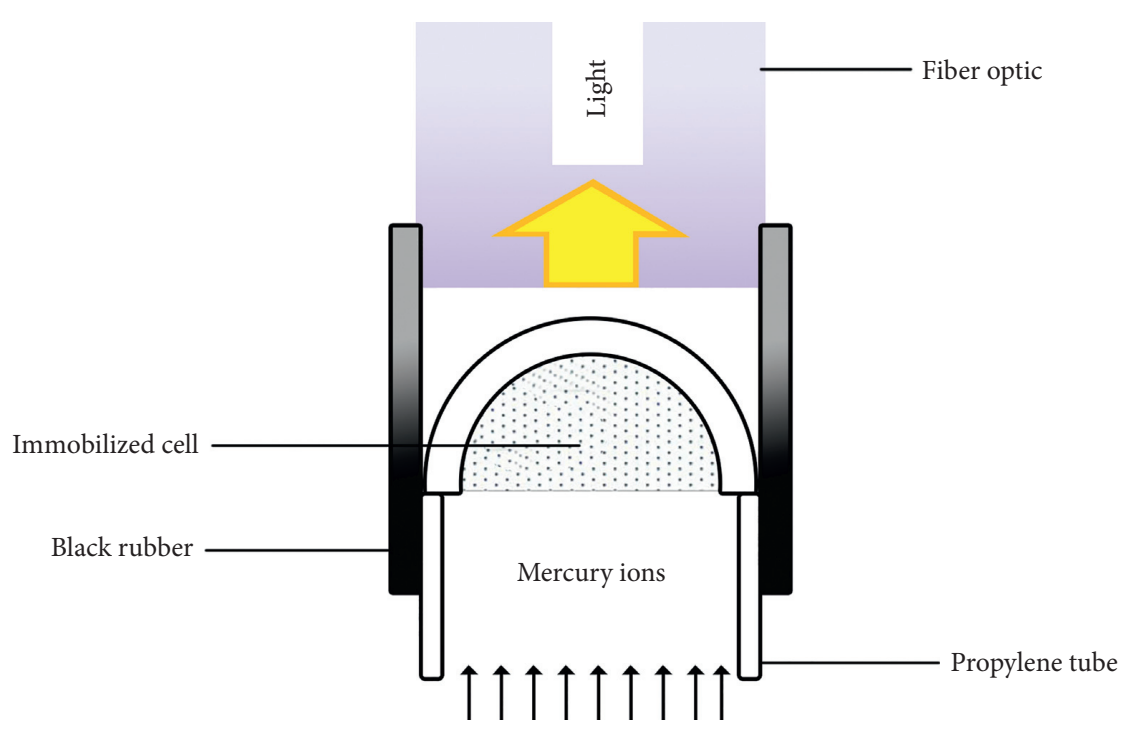

Figure 4: Schematic of the biosensor kit.

analyzed by AAS (Atomic Absorption Spectroscopy) to determine the mercury concentration.

2.5. Biosensor Operation. Different concentrations of the extracted mercury were prepared and stored in glass vials. After the bioluminescent (BL) test of the prepared biosensor, $5 \mathrm{ml}$ of the mercury was injected into the biosensor system. Rhamnolipid biosurfactant is a nonvolatile and nontoxic emulsifier. This will decrease the chance of mercury evaporation during the extraction process. Therefore, the developed biosensor system has good sensitivity.

\section{Results and Discussion}

3.1. Effect of Rhamnolipid Concentration on Mercury Extraction. Rhamnolipid biosurfactant as an emulsifier was used to increase the solubility of mercury in the aqueous phase. Because of the nontoxicity of rhamnolipid, the sensitivity of the biosensor was not affected during increasing the rhamnolipid concentration. Figure 5 shows the effect of rhamnolipid concentration on mercury extraction. The concentration of mercury in the aqueous phase has increased significantly with the increase in rhamnolipid concentration. This is due to the anionic biosurfactant and 


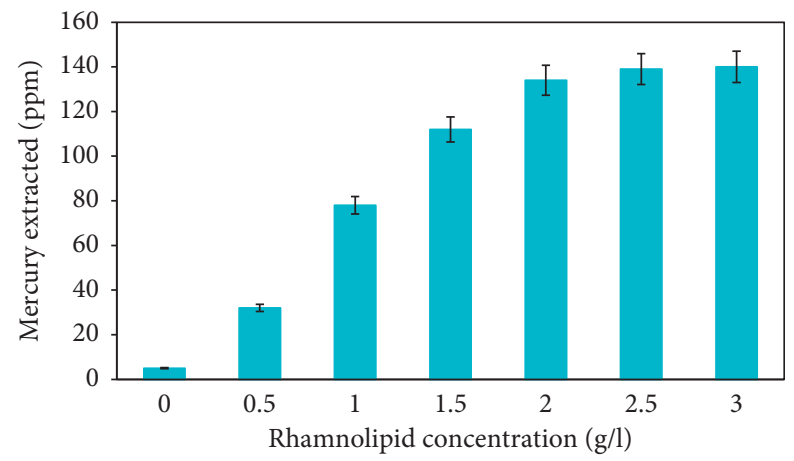

FIGURE 5: Effect of rhamnolipid concentration on mercury extraction.

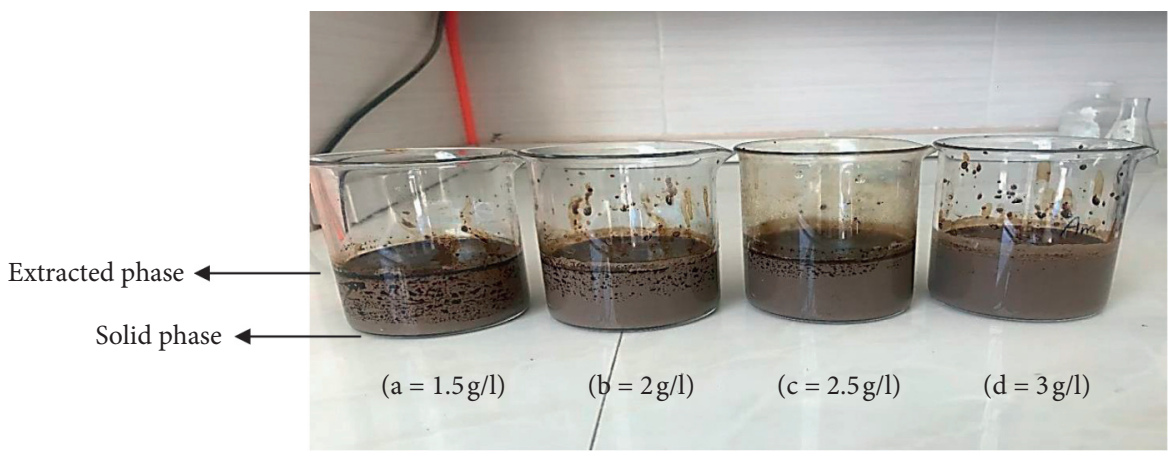

Figure 6: Extracted and solid phase during the metal removing process $\left(\mathrm{rpm}=200, T=25^{\circ} \mathrm{C}\right.$ ).

cationic metal interaction. The biosurfactant CMC (Critical Micelle Concentration) value of the rhamnolipid is about $100 \mathrm{mg} / \mathrm{l}$ [37]. The CMC of the biosurfactant can be raised by increasing the rhamnolipid concentration. Therefore, the mercury concentration is elevated in the aqueous phase. After $30 \mathrm{~min}$ of the extraction process of the rhamnolipid concentration of $3 \mathrm{~g} / \mathrm{l}$, the mercury concentration in the aqueous phase reached $150 \mathrm{ppm}$ (Figure 5). Figure 6 shows the extracted and solid phase during the metal removal process.

Figure 7 shows the concentration of extracted mercury via extraction time at the concentration of $3 \mathrm{~g} / \mathrm{l}$ of rhamnolipid. According to Figure 7, about $75 \%$ of mercury was extracted from the contaminated soils at the highest concentration $(3 \mathrm{~g} / \mathrm{l})$ of rhamnolipid. The yield of mercury extraction increases with increasing the extraction time. This happened due to an increase in the rate of micelle formation, which will enhance the mass transfer rate between the mercury ions and rhamnolipid biosurfactant. Figure 8 shows the microscopic image of the extraction process and the micelle formation of rhamnolipid. The aqueous phase penetrated the contaminated soil by rhamnolipid micelle formation, and the extraction process goes well.

3.2. Determination of the Optimum Aeration Rate. Immobilized $E$. coli cells in the biosensor kits floated in the LB. Due to lack of oxygen, bioluminescence bacteria activity is affected and light production is affected. The lack of a

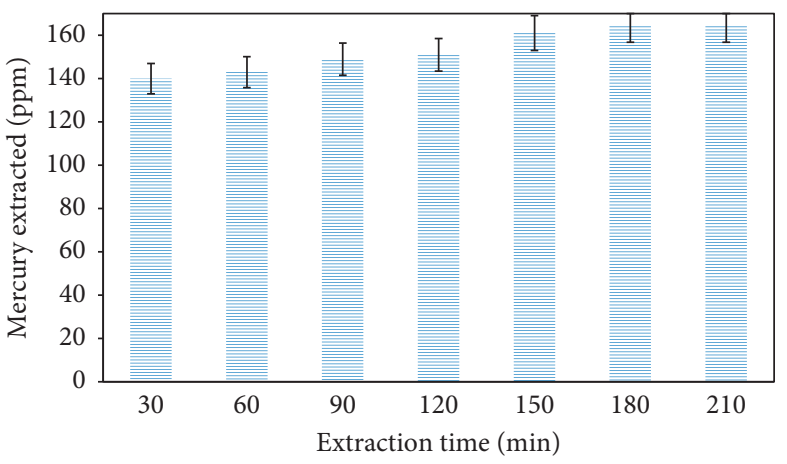

FIgURE 7: Concentration of extracted mercury via time of extraction at the concentration of $3 \mathrm{~g} / \mathrm{l}\left(\mathrm{rpm}=200, T=25^{\circ} \mathrm{C}\right)$.

sufficient oxygen supply would affect the BL of the immobilized cells since it is needed for the production of light. The designed biosensor was tested for three different aeration values (no aeration, 20-, and 40-ml air/min). Figure 9 shows how the aeration rate in BL affects the immobile cells. As shown in the fig, the BL values of the samples with no aeration and $40 \mathrm{ml}$ air/min both decreased close to zero after $50 \mathrm{~min}$. However, the other sample with an airflow rate of $20 \mathrm{ml} / \mathrm{min}$ reached the constant BL value of 200000 after $30 \mathrm{~min}$, and this value was constant for more than $50 \mathrm{~min}$. The results showed that Escherichia coli needs enough oxygen concentration for growing. The lack of adequate oxygen slows down the growth of immobilized bacteria. On the 


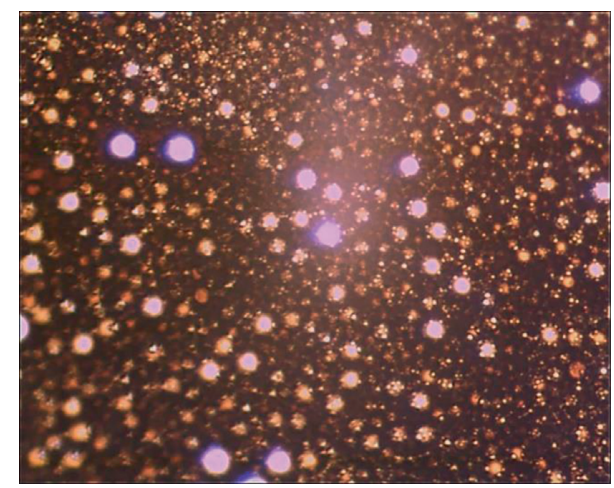

FIGURE 8: Microscopic image of the extraction process and micelle formation of rhamnolipid.

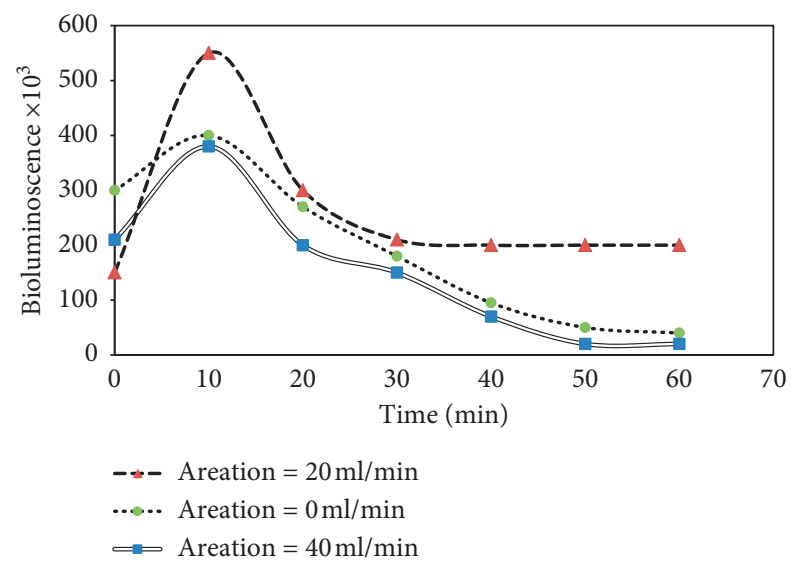

FIGURE 9: Effect of the aeration rate on the BL of the immobilized cells $\left(T=37^{\circ} \mathrm{C}\right)$.

other hand, the excess oxygen causes a decrease in the BL of the immobilized cells and inhibit bacterium growth. The optimum airflow rate of $20 \mathrm{ml} / \mathrm{min}$ was used for the experiments.

\subsection{Effect of Mercury Concentration on the Bioluminescence} Level of a Biosensor System. In this step, the extracted mercury in the micelle of the rhamnolipids was injected into the test reactor and biosensor kit. The effect of mercury concentration on the bioluminescence level of the biosensor system is shown in Figure 10. As shown in this figure, The Bioluminescence Level decreased quickly for the first time according to the mercury concentration, and then, after 30 min from injection decreased E. coli cells continued to slowly decrease after the initial drop in the BL value. The effect of mercury concentration on the bioluminescence level of the biosensor system is shown in Figure 10. As the concentration of the injected mercury is increased, the rate of BL value of luminescence bacteria decreased. The mercury toxicity causes inhibition in bacterial growth that resulted in decreasing the bioluminescence level of the bacteria [38]. As is shown in Figure 10, the concentrations of extracted mercury are well correlated with the mercury toxicity data

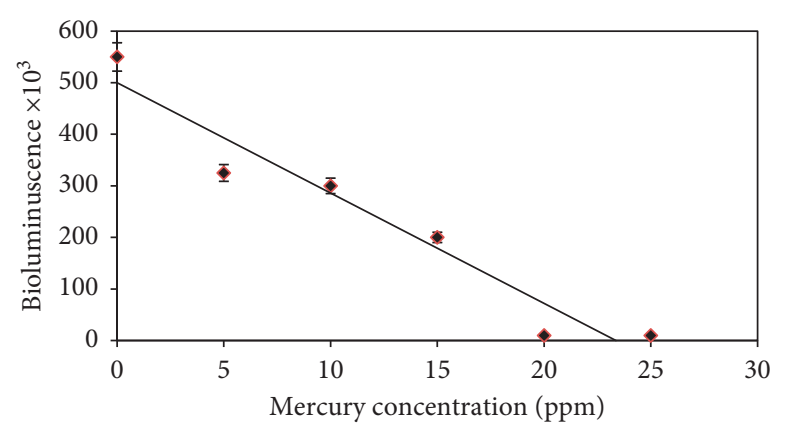

Figure 10: Effect of mercury concentration on bioluminescence level of biosensor system for 30 in after injection (aeration rate: $20 \mathrm{ml} / \mathrm{min}, T=37^{\circ} \mathrm{C}$ ).

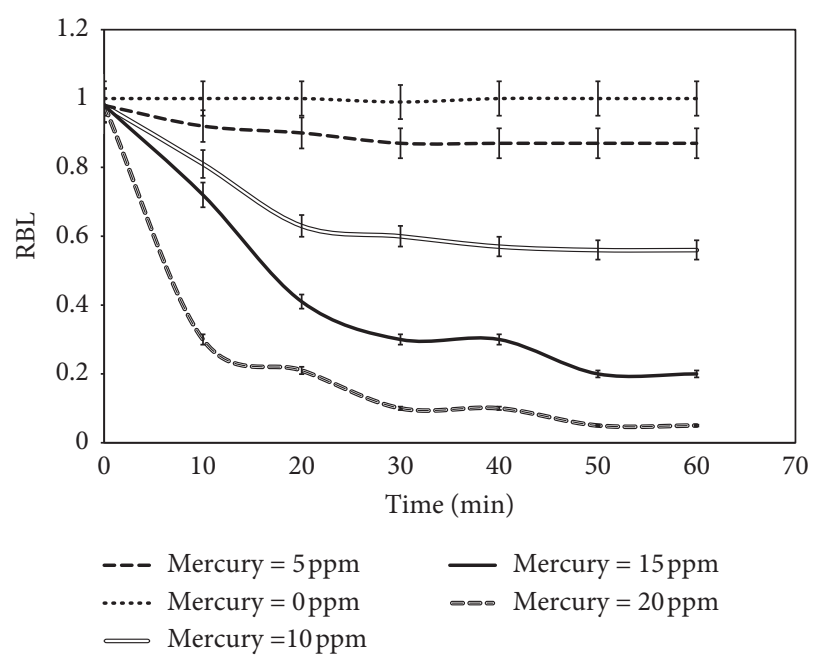

FIGURE 11: The variation of RBL with time for the biosensor system for different mercury concentrations (Aeration rate: $20 \mathrm{ml} / \mathrm{min}$, $\left.T=37^{\circ} \mathrm{C}\right)$.

achieved by a biosensor system, according to Figures 5 and 10 .

3.4. Bioluminescence Bacteria Performance. Inhibition of cellular metabolism due to the toxicity of mercury was observed in Escherichia coli MC106 cells. Similar concentrations of rhamnolipid without mercury were injected into the control biosensor system. The toxicity is determined using the equation below as Relative Bioluminescence $(\mathrm{RBL}=\mathrm{BL}$ in the test system/BL in the control system). Figure 11 shows the RBL variation with time in the biosensor system for different concentrations of the extracted mercury. The RBL value of the different concentration of mercury was measured as $1,0.9,0.6,0.35$, and $0.1 \pm 0.05$ for $0,5,10,15$, and $20 \mathrm{ppm}$ of mercury in the biosensor system at $30 \mathrm{~min}$ after injection. Using this value and Figure 11, the mercury concentrations could be calculated easily. A reduction in RBL of the system is seen due to the inhibition of the bacterial metabolism caused by toxic ions of extracted mercury [39]. 


\section{Conclusions}

In this work, a setup is designed to investigate the performance of Escherichia coli MC106 bacteria as a biosensor to detect mercury in contaminated soil. The rhamnolipid biosurfactant assisted in increasing the rate of mercury release from the soil to the aqueous phase. of the nontoxicity of rhamnolipid, it does not affect the accuracy of mercury concentration measurements. Results showed that the strong anion-cation interaction between rhamnolipid and mercury would cause an increase in mercury concentration in the aqueous phase by increasing in rhamnolipid concentration. The optimum airflow rate of $20 \mathrm{ml} / \mathrm{min}$ was estimated and used for the experiments. Escherichia coli MC106 cells show a reduction in its bioluminescent level with inhibition of the bacterial metabolism caused by toxic chemicals. The results that approved the designed biosensor are also able to detect the toxicity of mercury. Therefore, this proposed system has high potential as an in situ inspection technique because of its cheapness, simplicity, and rapid responses.

\section{Data Availability}

The data used to support the findings of this study are included within the article.

\section{Conflicts of Interest}

The authors declare that they have no conflicts of interest reported in this paper.

\section{References}

[1] G. Gleixner, "Soil organic matter dynamics: a biological perspective derived from the use of compound-specific isotopes studies," Ecological Research, vol. 28, no. 5, pp. 683-695, 2013.

[2] A. Smolander, R. A. Ketola, T. Kotiaho, S. Kanerva, K. Suominen, and V. Kitunen, "Volatile monoterpenes in soil atmosphere under birch and conifers: effects on soil $\mathrm{N}$ transformations," Soil Biology and Biochemistry, vol. 38, no. 12, pp. 3436-3442, 2006.

[3] R. A. Wuana and F. E. Okieimen, "Heavy metals in contaminated soils: a review of sources, chemistry, risks and best available strategies for remediation," Isrn Ecology, vol. 38, 2011.

[4] B. V. Tangahu, "Siti rozaimah sheikh abdullah, hassan basri, mushrifah idris, nurina anuar, and muhammad mukhlisin, a review on heavy metals (as, $\mathrm{Pb}$, and $\mathrm{Hg}$ ) uptake by plants through phytoremediation," International Journal of Chemical Engineering, vol. 38, 2011.

[5] P. C. Nagajyoti, K. D. Lee, and T. V. M. Sreekanth, "Heavy metals, occurrence and toxicity for plants: a review," Environmental Chemistry Letters, vol. 8, no. 3, pp. 199-216, 2010.

[6] Y. Yi, Z. Yang, and S. Zhang, "Ecological risk assessment of heavy metals in sediment and human health risk assessment of heavy metals in fishes in the middle and lower reaches of the Yangtze River basin," Environmental Pollution, vol. 159, no. 10, pp. 2575-2585, 2011.

[7] Z. Mijić, A. Stojića, S. Perišića, M. Rajšića, M. Tasića, and J. Radenkovićb, "Seasonal variability and source apportionment of metals in the atmospheric deposition in Belgrade," Atmospheric Environment, vol. 44, no. 30, pp. 3630-3637, 2010.

[8] F. Fu and Q. Wang, "Removal of heavy metal ions from wastewaters: a review," Journal of Environmental Management, vol. 92, no. 3, pp. 407-418, 2011.

[9] C. K. Ahn, "Removal of cationic heavy metal from aqueous solution by activated carbon impregnated with anionic surfactants," Journal of Hazardous Materials, vol. 164, no. 2-3, pp. 1130-1136, 2009.

[10] T. Kemper and S. Sommer, "Estimate of heavy metal contamination in soils after a mining accident using reflectance spectroscopy," Environmental Science \& Technology, vol. 36, no. 12, pp. 2742-2747, 2002.

[11] R. Krska, P. Schubert-Ullrich, A. Molinelli, M. Sulyok, S. MacDonald, and C. Crews, "Mycotoxin analysis: an update," Food Additives \& Contaminants: Part A, vol. 25, no. 2, pp. 152-163, 2008.

[12] V. Stone, B. Nowack, A. Baun et al., "Nanomaterials for environmental studies: classification, reference material issues, and strategies for physico-chemical characterisation," Science of the Total Environment, vol. 408, no. 7, pp. 17451754, 2010.

[13] F. Ferella, M. Prisciandaro, and I. De Michelis, "Removal of heavy metals by surfactant-enhanced ultrafiltration from wastewaters," Desalination, vol. 207, no. 13, pp. 125-133, 2007.

[14] S. E. Medvedeva, A. Tyulkova Nataliya, and M. Kuznetsov Alexander, "Bioluminescent bioassays based on luminous bacteria," Journal of the Siberian Federal University. Series: Biology, vol. 2, no. 4, pp. 418-452, 2009.

[15] Q. Gui, T. Lawson, S. Shan, L. Yan, and Y. Liu, "The application of whole cell-based biosensors for use in environmental analysis and in medical diagnostics," Sensors, vol. 17, no. 7, p. 1623, 2017.

[16] N. Hudson, A. Baker, and D. Reynolds, "Fluorescence analysis of dissolved organic matter in natural, waste and polluted waters-a review," River Research and Applications, vol. 23, no. 6, pp. 631-649, 2007.

[17] J. R. Van Der Meer and S. Belkin, "Where microbiology meets microengineering: design and applications of reporter bacteria," Nature Reviews Microbiology, vol. 8, no. 7, pp. 511-522, 2010.

[18] J. Chen, Z. Fang, J. Liu, and L. Zeng, "A simple and rapid biosensor for ochratoxin A based on a structure-switching signaling aptamer," Food Control, vol. 25, no. 2, pp. 555-560, 2012.

[19] H. Zou, W. Du, M. Ji, and R. Zhu, "Enhanced electrokinetic remediation of pyrene-contaminated soil through $\mathrm{pH}$ control and rhamnolipid addition," Environmental Engineering Science, vol. 33, no. 7, pp. 507-513, 2016.

[20] Y. Sun, K. Gao, Y. Zhang, and H. Zou, "Remediation of persistent organic pollutant-contaminated soil using biosurfactant-enhanced electrokinetics coupled with a zerovalent iron/activated carbon permeable reactive barrier," Environmental Science and Pollution Research, vol. 24, no. 36, pp. 28142-28151, 2017.

[21] L. H. Hansen and S. R. J. Sarensen, "Versatile biosensor vectors for detection and quantification of mercury," FEMS Microbiology Letters, vol. 193, no. 1, pp. 123-127, 2000.

[22] L. D. Rasmussen, S. J. Sørensen, R. R. Turner, and T. Barkay, "Application of a mer-lux biosensor for estimating bioavailable mercury in soil," Soil Biology and Biochemistry, vol. 32, no. 5, pp. 639-646, 2000. 
[23] P. Corbisier, E. Thiry, and L. Diels, "Bacterial biosensors for the toxicity assessment of solid wastes," Environmental Toxicology and Water Quality, vol. 11, no. 3, pp. 171-177, 1996.

[24] A. Ivask, M. Virta, and A. Kahru, "Construction and use of specific luminescent recombinant bacterial sensors for the assessment of bioavailable fraction of cadmium, zinc, mercury and chromium in the soil," Soil Biology and Biochemistry, vol. 34, no. 10, pp. 1439-1447, 2002.

[25] S. Leth, S. Maltoni, R. Simkus et al., "Engineered bacteria based biosensors for monitoring bioavailable heavy metals," Electroanalysis, vol. 14, no. 1, pp. 35-42, 2002.

[26] Q. Bristow, "An evaluation of the quartz crystal microbalance as a mercury vapour sensor for soil gases," Journal of Geochemical Exploration, vol. 1, no. 1, pp. 55-76, 1972.

[27] G. L. Turdean, "Design and development of biosensors for the detection of heavy metal toxicity," International Journal of Electrochemistry, vol. 2011, 2011.

[28] A. Ivask, T. Polyak, A. Kahru et al., "Fibre-optic bacterial biosensors and their application for the analysis of bioavailable $\mathrm{Hg}$ and as in soils and sediments from Aznalcollar mining area in Spain," Biosensors and Bioelectronics, vol. 22, no. 7, pp. 1396-1402, 2007.

[29] S. Jouanneau, M.-J. Durand, P. Courcoux, T. Blusseau, and G. Thouand, "Improvement of the identification of four heavy metals in environmental samples by using predictive decision tree models coupled with a set of five bioluminescent bacteria," Environmental Science \& Technology, vol. 45, no. 7, pp. 2925-2931, 2011.

[30] H. Khani, H. Khania, M. K. Rofoueia et al., "Multi-walled carbon nanotubes-ionic liquid-carbon paste electrode as a super selectivity sensor: application to potentiometric monitoring of mercury ion (II)," Journal of Hazardous Materials, vol. 183, no. 1-3, pp. 402-409, 2010.

[31] A. N. Kursunlu, M. Oguz, and M. Yilmaz, "On/off rhodamineBODIPY-based fluorimetric/colorimetric sensor for detection of mercury (II) in half-aqueous medium," IEEE Sensors Journal, vol. 19, no. 6, pp. 2009-2015, 2019.

[32] M. Sulak, A. N. Kursunlu, B. Girgin, Ö. Ö. Karakuş, and E. Güler, "A highly selective fluorescent sensor for mercury (II) ion based on Bodipy and Calix[4] arene bearing triazolenaphthylene groups; synthesis and photophysical investigations," Journal of Photochemistry and Photobiology A: Chemistry, vol. 349, pp. 129-137, 2017.

[33] A. N. Kursunlu, P. Deveci, and E. Guler, "Synthesis and spectroscopic-electrochemical properties of novel ratiometric $\mathrm{Hg}$ (II) chemosensor containing Bodipy and the N-phenylaza15-crown-5 moiety," Journal of Luminescence, vol. 136, pp. 430-436, 2013.

[34] R. Hajimohammadi and S. Johari-ahar, "Determination of optimal parameters of rhamnolipid biosurfactant production: an agent for emulsification of heavy crude oil," Petroleum Science and Technology, vol. 36, no. 3, pp. 186-192, 2018.

[35] G. Lan, Q. Fan, Y. Liu et al., "Rhamnolipid production from waste cooking oil using Pseudomonas SWP-4," Biochemical Engineering Journal, vol. 101, pp. 44-54, 2015.

[36] A. Rantala, M. Utriainen, N. Kaushik, M. Virta, A.-L. Välimaa, and M. Karp, "Luminescent bacteria-based sensing method for methylmercury specific determination," Analytical and Bioanalytical Chemistry, vol. 400, no. 4, pp. 1041-1049, 2011.

[37] S. A. Monteiro, G. L. Sassaki, L. M. de Souza et al., "Molecular and structural characterization of the biosurfactant produced by Pseudomonas aeruginosa DAUPE 614," Chemistry and Physics of Lipids, vol. 147, no. 1, pp. 1-13, 2007.
[38] M. Heinlaan, A. Ivask, I. Blinova, H.-C. Dubourguier, and A. Kahru, "Toxicity of nanosized and bulk $\mathrm{ZnO}, \mathrm{CuO}$ and $\mathrm{TiO}_{2}$ to bacteria Vibrio fischeri and crustaceans Daphnia magna and Thamnocephalus platyurus," Chemosphere, vol. 71, no. 7, pp. 1308-1316, 2008.

[39] T. J. Park, F. Sun, J. W. Seo, and K. K. Mehta, "Nanotechnologies for biosensor and biochip," Journal of Nanomaterials, vol. 2015, Article ID 420734, , 2015. 